ARTÍCULOS

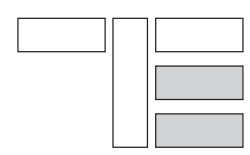



ISSN: $1130-3743$

\title{
CIUDADANÍA Y HUMANIDAD. LA EDUCACIÓN EN EL DISENSO
}

\section{Citizenship and humanity. Education in dissensus}

\section{Citoyenneté et humanité. L'éducation dans le dissentiment}

\author{
Fernando GIL CANTERO \\ Universidad Complutense de Madrid. Facultad de Educación. Centro de Formación \\ del Profesorado. Departamento de Teoría e Historia de la Educación. c/ Rector \\ Royo Villanova, s/n. Ciudad Universitaria. 28040 Madrid. Correo-e: gcantero@ \\ edu.ucm.es
}

Fecha de recepción: enero de 2008

Fecha de aceptación definitiva: abril de 2008

BIBLID [(1130-3743) 20, 2008, 25-44]

\section{RESUMEN}

La nueva asignatura de educación para la ciudadanía incluye referencias amplias a los derechos humanos. Este artículo discute la relación entre la formación para ejercer la ciudadanía y la formación en derechos humanos. Este artículo plantea los aspectos positivos y negativos de la relación entre ciudadanía y derechos humanos. Se propone diferenciar la educación cívica de la educación moral; se defiende la educación en el disenso como la aportación más significativa de los derechos humanos y se sugiere la conveniencia de elaborar una teoría educativa de los derechos humanos que nos ayude a elaborar un concepto de educación más cercano a los valores de los derechos humanos. Finalmente, se defiende la necesidad de formar a los alumnos en una idea de la dignidad humana.

Palabras clave: educación cívica, educación en derechos humanos, ciudadanía, humanidad, disenso, igualdad, dignidad humana. 


\section{SUMMARY}

The new subject of education for citizenship includes ample references to human rights. This article discusses the relation between education for exercising citizenship and education in human rights. This article raises the positive and negative aspects of the relation between the two. We propose to differentiate civic education from moral education; education in dissensus is defended as the most significant contribution of human rights and suggests the advisability of elaborating an educational theory of human rights that will help us to devise a concept of education closer to the values of human rights. Finally, the need to educate students in the idea of human dignity is defended.

Key words: civic education, education in human rights, citizenship, humanity, disenso, equality, human dignity.

\section{SOMMAIRE}

La nouvelle matière d'enseignement, l'éducation pour la citoyenneté comprend de vastes références aux droits humains. Cet article analyse la relation entre la formation pour exercer la citoyenneté et la formation en droits humains. On y aborde les aspects positifs et négatifs de la relation entre citoyenneté et droits humains. Le but de l'article est de différencier l'éducation civique de l'éducation morale. L'éducation dans le dissentiment est posée comme la contribution la plus significative des droits humains et on suggère la convenance d'élaborer une théorie éducative des droits humains qui puisse nous aider dans l'élaboration d'un concept d'éducation plus proche aux valeurs des droits humains. Finalement, la nécessité de former aux élèves dans une idée de la dignité humaine est proposée.

Mots clef: éducation civique, éducation en droits humains, citoyenneté, humanité, dissentiment, égalité, dignité humaine.

\section{INTRODUCCIÓN}

Una de las características más sobresaliente del conocimiento pedagógico es su carácter necesariamente abierto. Se nutre de otras realidades buscando su transformación en acciones pedagógicas, esto es, en propuestas de acción intencionales. Por eso, nos interesa, nos tiene que interesar todo lo que puede contribuir o, en su caso, dificultar la formación de los sujetos. Esto obliga a los pedagogos a estar permanentemente alerta, para que nada de interés educativo se nos pase, pero también para que nada nos deslumbre más de lo aconsejable.

Uno de los errores más habituales de los pedagogos, en ocasiones, señalado por otros profesionales, es nuestra tendencia a sentir un entusiasmo irrefrenable ante una nueva realidad susceptible de educar. Generalmente creemos que hemos 
encontrado, por fin, lo definitivo... llegando así a confundir las partes con el todo. No estaría nada mal que la formación de los pedagogos incluyese alguna prueba de prudencia, sensatez, sentido común y, parafraseando a Gadamer, de la capacidad de "dejar valer en mí algo contra mí, aunque no haya ningún otro que lo vaya a hacer valer contra mí" (Gadamer, 1977, 438).

Pues bien, como es sabido, se ha considerado que la referencia a los derechos humanos en la nueva asignatura de educación cívica provocaría diversos efectos, digamos, beneficiosos a la misma. Este artículo trata de mostrar las dificultades y, en algunos casos, trampas que acarrea esa vinculación. Y más allá, y como origen de la argumentación, el desdibujamiento de algunos pilares clásicos del concepto de educación. Pero antes de comenzar el desarrollo de estas ideas quiero aclarar, brevemente, a qué me refiero con "efectos beneficiosos".

Quienes hayan seguido de cerca el debate sobre la asignatura habrán comprobado que una de las quejas principales es que se inmiscuye en la orientación moral particular de las familias y sujetos, más allá, según algunos, de un pluralismo adecuado a la convivencia democrática. Pues bien, este grupo no suele cuestionar la referencia en el título y en el contenido a los derechos humanos cuando, precisamente, es esta presencia la que ha permitido al legislador entrar hasta la cocina en cuestiones morales y de ética de la felicidad, entendida en términos clásicos como preceptos particulares o privados. Por el otro lado, esa misma referencia a los derechos humanos es el argumento de los defensores de la propuesta del gobierno para contrarrestar cualquier acusación sobre adoctrinamiento moral. Estos derechos actuarían así de límite, freno o muralla para evitar inmiscuirse en visiones morales particulares. ¿Quién se equivoca? ¿Cuál es, entonces, el efecto beneficioso de vincular la ciudadanía con los derechos humanos?

En realidad, nos encontramos con diversas formas de concebir el papel de los derechos humanos en las sociedades democráticas y, por tanto, y por derivación, en las situaciones educativas. Vamos a desgranar este supuesto y a confrontarlo con las dos posturas contradictorias planteadas anteriormente.

\section{VACIADO MORAL DE LA ESCUELA}

Como hemos mostrado en otros textos (Jover, Casares, Gil y Payá, 2001) las tendencias postmodernas han desdibujado los límites morales de los comportamientos públicos y privados. Hay que irse a los extremos y, sobre todo, a los actos con violencia para que haya un claro consenso sobre lo que está mal y bien. Estas tendencias han provocado, como es lógico, un desdibujamiento acerca de los límites normativos de la educación: salvo en los extremos tampoco hay un consenso definido sobre qué es más educativo, qué educa más. 
Toda acción educativa conlleva una orientación moral ${ }^{1}$. Por eso, es probable que una de las manifestaciones de la tan manida crisis de la educación sea, precisamente, la ausencia de una clara orientación moral o, lo que es lo mismo, la presencia de múltiples orientaciones posibles, todas válidas. Este desdibujamiento normativo se debería, entre otras razones, a un paulatino vaciado del alcance o significado moral de las acciones humanas, tanto públicas como privadas. La educación pierde peso, pierde identidad, significado, delimitación, normatividad, en función del vaciado que a su vez hagamos del alcance moral de los actos humanos $^{2}$. Al igual que la sociedad, las costumbres, los valores familiares y, en general, todo el dinamismo antropológico de la postmodernidad nos han llevado a una concepción ligera de la conciencia, donde, salvo determinados extremismos, es difícil señalar qué está bien o mal, la escuela, por su parte y, como decía, de igual modo, ha sufrido un paulatino y creciente vaciado moral, en algunos casos, tan acentuado que cualquier propuesta legislativa, o profesor, o texto, o teoría, etc., que marque algo una orientación de valor frente a otras nos parecerá escandalosamente adoctrinante o, por lo menos, peligrosa. Esta tesis la puede comprobar cualquiera con cierta memoria: todas las reformas legislativas que más escándalo han causado (democratización, itinerarios, esfuerzos, repeticiones, etc.) se deben a la orientación moral y hasta antropológica que se les ha atribuido, acertadamente o no.

No es éste el momento para analizar con detenimiento estas hipótesis. Sí lo es, en cambio, para observar que, a nuestro juicio, una de las razones de las numerosas y ruidosas protestas que ha provocado la propuesta de una asignatura sobre "educación cívica y derechos humanos" se debe a que, precisamente, rompe ese desdibujamiento normativo apostando por una orientación moral determinada. La oposición a esta asignatura no es la oposición a recibir una formación cívica sino a acentuar ciertas perspectivas éticas sustantivas, con peso, definidas, en la escuela.

Ahora que las aguas se van tranquilizando ya puede afirmarse que lo que llegó a constituir, para algunos, una seria amenaza de formación para los jóvenes y los padres, se ha quedado en unos fuegos artificiales muy devaluados, poco ruidosos y nada originales. Así, la fundada preocupación inicial por parte de algunos sectores sociales de una única visión moral de la nueva asignatura en detrimento de otras perspectivas no parece sostenerse, como lo demuestra echar un vistazo sosegado a algunos manuales. Hay libros muy discordantes con la realidad cívica actual y otros más sosegados y menos críticos, hay textos algo revolucionarios y otros

1. Ésta es, por cierto, la tesis sustantiva -de origen- del más irreverente, crítico y politizado texto de educación para la ciudadanía que ha sido publicado hasta la fecha: Fernández Liria, FerNáNDEz LiRIA y Alegre Zahonero, 2007.

2. Una de las formas de vaciado ético habitual estriba en mostrarse indiferente ante el significado humanizador de los actos (IBÁÑEz-MARTín, 2000, 241) en el sentido de considerar factibles para su formación cualquiera de ellos siempre que se mantenga dentro de la legalidad vigente. Consideramos que esto no mejora el juicio educativo, más bien lo desnormativiza o estira tanto que rompe la sustantividad de su alcance. 
muy vinculados a la mentalidad dominante. Las editoriales, en definitiva, el mercado, ya se han encargado de poder tener cuota de ventas en todos los sectores y colegios. La diversidad de enfoques también se mantiene y amplía a través del profesorado: los habrá, como pasaba con los manuales, con una visión muy crítica de nuestra sociedad y otros con valoraciones muy conformistas. En definitiva, la asignatura, por sí misma, en sus contenidos legales, permite múltiples visiones, desde las más políticamente conservadoras a las más radicales, como variadas son las interpretaciones o perspectivas sociales y morales sobre los valores de la convivencia y la felicidad.

Tampoco parece sostenerse la idea de que la nueva asignatura supone una novedad radical en el panorama del currículo o de la formación de valores en la escuela. Aceptar este supuesto significaría asumir que la escuela vive aislada de las nuevas propuestas legislativas o cambios de valores dominantes en nuestra sociedad. O que los contenidos tradicionales de la Filosofía, la Ética o las CC. Sociales no recogen nada de lo que pasa o se hace en nuestra sociedad. O que tampoco las familias, las aulas, los medios de comunicación, el profesorado, se hacen eco de algún modo de lo que ocurre en su entorno político, social y cultural. Es difícil de sostener que con la nueva asignatura nuestros alumnos van a oír algo que nunca, jamás, hubiesen conocido por ninguna otra vía formal e informal. Igualmente exagerado es defender que en apenas una hora a la semana se va a alterar la formación moral de nuestros jóvenes ${ }^{3}$.

Pero el debate y, sobre todo, su proceso, su dinámica, ha permitido reconocer aspectos positivos y negativos (Naval y Jover, 2006). Me gustaría hacer referencia a varios hechos que, vistos desde determinada perspectiva, pueden contemplarse como síntomas de la realidad educativa y, en especial, como síntomas del modo en que encaramos nuestros problemas educativos y, sobre todo, los definimos o enunciamos.

Parece evidente que, desde una perspectiva de política partidista, la educación se ha ido enconando y siendo objeto de un mayor enfrentamiento. En nuestro país, como se sabe, para poder reconocer las diferencias ideológicas entre votar al Partido Popular o al Partido Socialista Obrero Español basta con atender a las medidas sobre educación. Es ahí donde los votantes pueden encontrar con claridad las distintas posturas. En realidad es donde se puede encontrar todavía algo de politica e incluso de antropología. En efecto, la educación no es sólo el escaso espacio que queda de lucha política en el que se enfrentan los grandes partidos sino que permite, asombrosamente, construir identidad. A través de la educación se producen los fenómenos de situarse políticamente, hasta de descubrir tus simpatías

3. No pretendemos, en modo alguno, menospreciar el alcance de obligar, aunque sea una hora, a recibir enseñanza de una asignatura. Todo lo contrario: debería adoptarse como principio político que la incorporación de una nueva materia del currículo de los niveles obligatorios requiera, por lo menos, el consenso entre los grupos políticos mayoritarios. 
políticas y, si apuramos el argumento, hasta de detectar tus sintonías antropológicas. Así ocurrió, por ejemplo, con la famosa referencia al esfuerzo. Que esto dé margen para un debate político tiene muchas interpretaciones, pero una de las más llamativas es la necesidad de construir identidad política en los temas educativos, inflar una cuestión, obvia para todos, buscando el matiz partidista, la mirada políticamente diferenciadora ${ }^{4}$. Porque ¿quién puede estar en contra del esfuerzo en la educación? Y del mismo modo ¿quién puede estar en contra de la educación cívica, de la formación en valores cívicos o en los derechos humanos?

Hay que reconocer que la propuesta legislativa de introducir obligatoriamente la asignatura de educación parta la ciudadanía ha roto la indiferencia con respecto al significado formativo o no del contenido de esa materia. Hasta el punto de que en más de una ocasión el debate sobre esta asignatura ha pasado a consistir en un debate sobre la educación en valores, así directamente. Y esto, insisto, en sí mismo, para los cultivadores de la pedagogía es una buena noticia 5 .

Pero, por otra parte, resulta lamentable observar cómo la politización del espacio educativo y escolar, por unos y otros, cómo los enfrentamientos sistemáticos por cualquier cuestión van a ir aumentando el vaciado de contenido sustantivo acerca de lo ético ${ }^{6}$ y, por tanto, el contenido pedagógico valorativo. Parece como si, en realidad, se desease un perfil suave, nada acentuado, escasamente normativo de la escuela... puro zumo de boina. Más aún, parece como si todo el mundo asumiese la importancia de la influencia moral que puede darse en cada aula cerrada donde un profesor puede afirmar o negar algo, pero que no preocupa mientras se mantenga en una especie de normalidad silenciosa, sin despuntes en un extremo o en otro, política y diplomáticamente correcto como un vendedor. Y que con cada intento de acentuar, remarcar, subrayar una visión, unos valores frente a otros, se levantase todo tipo de suspicacias.

Nuestra propuesta es que todos ganamos, especialmente, las nuevas generaciones, cuando recuperamos una visión sustantiva de la educación, cuando ipor fin! algunos padres se preocupan por lo que pueda trasmitirles la escuela a sus hijos, cuando del puro zumo de boina pasamos a una trasmisión de una hipótesis comprensiva del mundo, una visión ética, sólida, omnicomprensiva de la realidad, una visión dura de la educación como proceso de cambio teleológico hacia unos valores u otros. Deberíamos alegrarnos cuando profesores y escuelas hacen una afirmación

4. Más aún, en realidad sospecho que se trata de aprovechar cualquier oportunidad para construir identidad política, partidismo, una cierta saludable necesidad de situarnos por oposición.

5. Considero que hay una especie de regla de proporcionalidad: cuanto más diplomática, blanda, equidistante de todo es la educación, más susceptible es de terminar ocupándose de seudovalores, trivialidades ecológicas o modas televisivas. La escuela se llena de moralina seudodemocrática y política en la medida en que se vacía de los significados normativos sobre la educación, la persona educada $\mathrm{y}$, en definitiva, el significado moral de las acciones humanas.

6. No podemos ocuparnos de este asunto tan determinante, pero ¿cómo suscitar educación sin una idea de felicidad? 
fuerte de sentido de realidad, una trasmisión de tradición significativa para comprender el mundo y comprendernos en él. No hay educación, como cambio personal de valoración, sin una afirmación de valor de esa misma realidad.

\section{Ciudadanía y humanidad}

El emparejamiento entre ciudadanía y derechos humanos con respecto a una asignatura, obligatoria y nueva en el currículo, creemos que puede llegar a ser equívoco para ambas partes. Casi siempre que se juntan diferentes categorías, la mayor termina desdibujando a la pequeña, evitando que se perfile nítidamente lo que se pretende, en nuestro caso, con la educación cívica. Afirmar que todos los ciudadanos son seres humanos, a estas alturas, puede resultar, si no se delimita claramente el propósito, una perogrullada confusa e interesadamente sesgada. Además, como vamos a mostrar, este equívoco afianza y arrastra otros muy definitorios de nuestra época y, por tanto, también de la educación.

En otro momento sugerimos la conveniencia de delimitar la educación cívica de la educación moral. Hay una línea continua que va desde los aprendizajes de valores y costumbres más locales a los aprendizajes de perspectivas más universales. Esta línea se observa, sobre todo, en el modo de argumentar frente a los alumnos los acontecimientos de nuestro entorno, pudiendo referirnos a explicaciones más circunscritas a razones locales, idiosincrasias propias de nuestro país, o a visiones más universales, más antropológicamente definitorias de la condición humana, más cercanas a una ética universal. Esta línea continua que alterna argumentos y visiones locales con perspectivas más universales es una estrategia educativa acertada (Gil y Jover, 2003).

Sin embargo, como ya se ha indicado, también es muy acertado educativamente delimitar la educación cívica y la educación moral. Y esta diferenciación es la que queremos resaltar aquí, en este momento, porque pensamos que la propuesta de la nueva asignatura, en su denominación y contenido, puede terminar confundiendo ambos planos. La confusión es negativa tanto para los objetivos concretos de la ciudadanía como para los referidos a la formación moral. Y también lo es, y con esto incluimos los síntomas de nuestra época a los que nos referíamos antes, para la percepción del valor ulterior de la libertad y la intuición ética del sentido de la justicia. Veámoslo con más detalle.

No vamos a defender aquí que la educación cívica nada tiene que ver con los valores de los derechos humanos cuando, sobre todo, se desarrolla en contextos democráticos. Lo que sí queremos señalar es que el mantenimiento o no de los valores cívicos concretos de nuestra convivencia, en forma de costumbres o leyes, sería más dinámico, cambiante y, por tanto, susceptible de mejorar si, precisamente, no se identifican miméticamente con la expectativa humanizadora general que trasmite la moral de los derechos humanos. Es fundamental mantener en la sociedad márgenes de libertad de pensamiento y de acción. Y una de las formas de colaborar 
directamente en mantener y acrecentar esa libertad estriba en no identificar nuestros valores, leyes y costumbres dominantes con los valores de los derechos humanos, con la verdad cerrada y única de la humanización del ser ciudadano ${ }^{7}$.

El poder, en todas sus formas de expresión, tiende a concepciones estáticas y cerradas de la convivencia y la moral. La propuesta gubernamental sobre esta asignatura no se escapa de este principio. Y su forma de expresarlo ha consistido en vincular la educación de la ciudadanía con los derechos humanos. Al unir ambas realidades pretende legitimar moralmente un estado de cosas, valores, leyes y costumbres. Pretende autorizarse, a sí mismo, en los diversos contenidos que quepa trasmitir para formar ciudadanos mientras se mantenga dentro de los derechos humanos. Ésta es la forma más extendida y peligrosa de atontar a la ciudadanía en contextos democráticos: trasmitir la idea de que la legitimidad moral de las iniciativas políticas se mantiene dentro de los derechos humanos. Es decir: que una vez asimilada, identificada, argumentada una ley, costumbre, valor o propuesta del rango que sea a los derechos humanos, queda cerrado el debate ético.

La fuerza moral de los derechos humanos radica, precisamente, no en el poder que emana de su texto o articulación de derechos sino en las intuiciones ${ }^{8}$ que sobre la condición humana y su dignidad abre como horizonte permanente de disenso. La fuerza legitimadora de los derechos humanos no radica tanto en lo ya logrado, a través de cortes penales internacionales o textos internacionales, sino en las expectativas permanentes de humanización que abre al reconocer como valor absoluto inarticulado del todo por ningún gobierno, nación o cultura, la expresión del ser humano. La fuerza de los derechos humanos se encuentra, precisamente, en lo que no podemos concretar de una vez por todas y para siempre: las ideas que el ser humano barrunta, va barruntando sobre lo justo y lo bueno, incluso, para llegar a estados de conciencia (Touriñán, 2003, 230-231) y visiones de humanización superadores de los propios derechos humanos actuales?.

7. D. Kiwan mantiene la tesis de que la ciudadanía se refiere a una perspectiva "localizada" de la idea de humanidad contenida en los derechos humanos (KIwan, 2005).

8. Para ver la relación entre ciudadanía ética e imaginación narrativa: NussBaum, 2002, 299 y ss.

9. El libro que ha publicado Victoria Camps sobre la educación para la ciudadanía termina refiriéndose a la conveniencia de "[...] rechazar dos teorías igualmente falsas. Una, que existe una naturaleza humana invariable, que debe persistir en el tiempo. Otra, que existe la alienación de una supuesta humanidad esencial, por causa de la represión social, como creyeron Rousseau y Marx. Lo único que realmente existe es la formación del ser humano, a través de la socialización, seguida de la autoindividuación" (2007, 42). Se equivoca de raíz en ambas cuestiones. Pero lo que querría evitar es que se identifique nuestra tesis con la mencionada de Camps: reconocer un horizonte crítico permanentemente abierto en los derechos humanos no es incompatible con una idea de la condición humana. Ya nos enseñó Gadamer, basándose en Aristóteles, que la función de una idea natural del derecho no es defender la invulnerabilidad de un estado de cosas, sino todo lo contrario: el poder oponernos a ese estado de cosas: "No son por lo tanto (los derechos humanos) normas escritas en las estrellas o que tuvieran su lugar inalterable en algún mundo natural moral, de modo que sólo hubiera que percibirlas. Pero por otra parte tampoco son meras convenciones, sino que reflejan realmente la naturaleza de las cosas; sólo 
Aunque el paralelismo no sea estéticamente llamativo, permítaseme hacer la comparación de los derechos humanos como un lenguaje más, un esperanto, que aspira a la máxima universalización y extensión, pero que su máximo efecto moral estriba en no ser el final de ninguna trayectoria sino la apertura de muchas más. Un lenguaje, entre otros, que no trata de cerrar el paso a nuevas formas de ver lo bueno porque se sabe permanentemente deudor de su fuente de ser: la condición humana y la búsqueda excelsa de la expresión más humanizadora de su dignidad.

\subsection{Constitución y derechos humanos}

El horizonte moral inmediato de la ciudadanía, en tanto que ciudadanía y sin cambiar de orden jerárquico, es la Constitución, no los derechos humanos. Esto nos permite recoger la tradicional y acertada diferencia jurídica entre derechos fundamentales de un ordenamiento constitucional determinado y derechos humanos como horizonte crítico de realización.

La distinción clásica, en nuestro entorno, es la propuesta por Pérez Luño al mantener que los derechos fundamentales, «[... ] sólo describen el conjunto de derechos y libertades jurídica e institucionalmente reconocidos y garantizados por el derecho positivo", mientras que los derechos humanos "[...] aúnan a su significación descriptiva de aquellos derechos y libertades reconocidos en las Declaraciones y Convenios internacionales, una connotación prescriptiva o deontológica, al abarcar también aquellas exigencias más radicalmente vinculadas al sistema de necesidades humanas, y que debiendo ser objeto de positivación no lo han sido" (Pérez Luño, 1986, 46).

Cuando se utilizan indistintamente las expresiones "derechos humanos" y "derechos fundamentales" o constitucionales hay que advertir que, en la mayoría de los casos, se está partiendo de la perspectiva de que el único Derecho existente es el ordenamiento jurídico imperante. Los derechos fundamentales, desde este enfoque, serán identificados con los derechos humanos que han sido positivizados: recogidos, manifestados y garantizados en un orden constitucional concreto. Fuera de este marco, se dirá, no hay en rigor derechos humanos en el sentido jurídico del término, esto es, como instancia a la que poder recurrir.

Cuando, por el contrario, se defiende un concepto de los derechos humanos diferenciado de los derechos fundamentales, lo que se pretende es resaltar la existencia real de aquéllos, el carácter prescriptivo o deontológico de algunos derechos, radicalmente vinculados a las necesidades humanas, aunque no hayan sido todavía objeto de positivación como derechos fundamentales por el ordenamiento jurídico particular de que se trate.

que ésta sólo se determina a su vez a través de la aplicación a que la conciencia moral somete a aquéllas" (GADAMER, 1977, 391 y ss.). 
La diferencia señalada es importante, sobre todo, por dos razones. En primer lugar, porque permite denunciar violaciones de los derechos humanos en países en los que carecería de sentido hacerlo desde los derechos fundamentales de sus respectivos ordenamientos jurídicos. En segundo término, muy relacionado con lo anterior, porque nos ayuda a reconocer como horizonte crítico de la convivencia una serie de derechos del hombre que pueden cuestionar y alentar la mejora de los derechos fundamentales del país de que se trate.

Gracias a estas distinciones es posible establecer que la capacidad de reconocer nuevas y mejores posibilidades de humanización no contempladas todavía, en parte o en su totalidad, en un ordenamiento jurídico concreto no depende sólo de un mero análisis crítico sobre la estructura y el funcionamiento interno de ese ordenamiento (o de esa ciudadanía concreta) sino principalmente de mantener una reflexión ética sobre las aspiraciones o expectativas morales de los hombres hacia formas de vida más humanas. Por eso se ha señalado que «[...] una vía a la humanización de la humanidad tenga necesariamente que pasar por la crítica y el cambio en las convicciones [...]”(García Carrasco, 2007, 197).

Es necesario insistir para evitar interpretaciones erróneas que la delimitación señalada no pretende en modo alguno restar importancia al enfoque legalista de los derechos humanos. Muy al contrario, pues a nadie se le escapa que estos derechos sólo pueden llegar a ser realmente efectivos cuando quedan plasmados en un ordenamiento constitucional concreto. Como indica Hierro, "[...] el orden legal que la concepción de los derechos humanos requiere como "justo" implica, al menos, dos consecuencias básicas: en primer lugar que los derechos humanos queden situados (declarados y protegidos) en un escalón normativo superior al de la legislación ordinaria y, en segundo lugar, que sean susceptibles de protección jurisdiccional frente al legislador" (Hierro, 2002, 34). Ahora bien, si no nos conformamos con lo que ya tenemos, si además pensamos que se puede y se debe aspirar a humanizar más la convivencia y que hay que extender estos derechos allí donde no están reconocidos o no se cumplen, entonces habrá que observar que nuestra tarea radical estriba en permanecer activamente implicados en proyectarnos hacia una toma de conciencia de lo humanamente justo cuyo punto de referencia no podrá limitarse al conjunto de derechos fundamentales ya establecidos, ni incluso a un estado de conclusión de logro de unos derechos humanos ${ }^{10}$.

10. La perspectiva legalista y vinculada a la importancia de una concepción del Derecho como Poder la desarrolla, como es habitual, Peces BARBA e insiste de nuevo en ella, acertadamente, en su libro para esta asignatura (2007). Sin embargo, la limitación a su propia concepción y, por tanto, la necesidad de creerse, de verdad, el disenso y el pluralismo, cuando se piensa en los derechos humanos, puede observarse tras leer este texto ideológicamente preconstitucional: "Me temo que los idearios de los centros privados no tengan esa visión total de la ciudadanía, de bien común y de interés general, sino más bien favorezcan la fragmentación y la mentalidad de sociedad privada. La formación de catecismo con creyentes que parten de una fe o que aceptan los dogmas de una Iglesia o de una corriente filosófica puede proporcionar profesionales competentes, pero no son buena base para la preparación de ciudadanos inteligentes y libres" (PeCEs-BArbA, 2006, 31). 
En definitiva, el equívoco que se abre al vincular la ciudadanía con los derechos humanos tal y como queda regulado en el diseño curricular general de esta nueva disciplina estriba en usar la categoría mayor y universal como legitimadora de un consenso sobre lo ciudadano, otorgando a ésta el horizonte de lo moral. Error. La presencia de los derechos humanos, de la idea de humanidad, alcanza su máxima expresión cuando se percibe como el horizonte crítico de disenso (Muguerza, 2007) de las diferentes propuestas legislativas o morales sobre una categoría determinada de ciudadanía.

\section{Derechos humanos y bases éticas de la educación}

Ya que los derechos humanos han hecho su aparición, con todas las limitaciones que se consideren, en el currículo escolar, tal vez sea un buen momento para señalar algunas implicaciones de estos derechos en la educación.

En efecto, sería un error reducir las posibilidades pedagógicas de los derechos humanos a su enseñanza como contenido cultural (Mestre, 2007). En el apartado anterior ya hemos visto que estos derechos pueden proporcionar sobre todo un adecuado marco interpretativo de la ciudadanía al establecer un horizonte crítico en torno a la idea de humanidad y humanización. Pues bien, con más sentido aun, ese marco interpretativo de los derechos humanos puede ser aplicado a la educación para, del mismo modo, reconocer su incidencia en los valores de la formación humana. Y es que, en realidad, la incorporación de una nueva asignatura en el currículo, especialmente centrada en la trasmisión de valores y no sólo de contenidos culturales, nos obliga, como pedagogos, a considerar el alcance práctico y epistemológico de los principios de procedimiento. Como se sabe y está muy asumido en los conocimientos de la Teoría de la Educación, la enseñanza de valores exige, sobre todo, la ejemplificación docente y la presencia activa y permanente, durante todo el proceso de enseñanza, de los valores que deseamos mostrar al alumnado. Suscitar situaciones educativas desde los derechos humanos y, de modo mucho más significativo, aprovechar situaciones imprevistas para reconducirlas con una intencionalidad educadora centrada en estos derechos, exige pensar la educación y lo educativo desde el marco reflexivo que nos proporcionan, en su conjunto, los derechos humanos ${ }^{11}$.

Esta propuesta parte del presupuesto de que la tarea de educar sólo puede conceptualizarse y practicarse hoy desde el horizonte moral de humanización al que apuntan los derechos humanos. Cualquier consideración acerca de las exigencias normativas de la educación, como proyecto de humanización, requiere hoy realizarse desde y a través de la idea de condición y dignidad humana contenida

11. Estaríamos ante una teoría educativa de los derechos humanos (Gil, 2003) que se complementaría muy bien con una teoría educativa del diálogo y la comunicación (SORIANO, 2007; AyUSTE, 2006; MARTínEZ y Hoyos, 2006). 
en los derechos humanos. El perfil de una persona educada y, por tanto, del concepto mismo de educación y de lo educativo, pasa hoy por reconocer estos derechos y los valores que representan. En la medida en que se amplían las reflexiones sobre los derechos humanos, lo hace también la idea de humanización y, por lo mismo, de educar ${ }^{12}$. En efecto, la educación no es sólo derecho humano para su implantación alfabetizadora. La educación ha de ser impartida en sus contenidos y formas de tal modo que se constituya en un auténtico derecho humano. Puede haber así sistemas educativos, escuelas y educadores que vulneren el derecho a la educación como derecho humano porque no promueven una auténtica y relevante humanización ${ }^{13}$.

Los derechos humanos pueden ayudar a los educadores a comprender que su tarea se debe desarrollar desde una perspectiva humanizadora encaminada a que los educandos alcancen proyectos de vida, personales y sociales, más humanos y a que los desarrollen mediante un trato más humano. Los derechos humanos contribuyen decisivamente a resaltar parte de las bases éticas de la educación porque nos ayudan a comprender el significado bumanizador de las finalidades educativas. Nos ayudan a comprender que cuando afirmamos que la tarea educativa trata de favorecer el desarrollo personal, de ayudar a lograr proyectos de vida, de alcanzar una posición personal en la existencia o de aspirar a una vida más humana, este proyecto tiene en los derechos humanos el reconocimiento jurídico y ético de mínimos necesarios para establecer qué valores resaltan la condición humana. Los educadores que, además de enseñar estos derechos, pretenden hacer de la educación un derecho humano son los que, a su vez, les guía el interés pedagógico de resaltar lo más humano de sus alumnos, lo más universal, los horizontes de existencia más abiertos y seguros desde la búsqueda de sí mismos, de su identidad particular, de su proyecto de vida. Comprender el significado humanizador de las finalidades educativas, desde los derechos humanos, supone en realidad mostrar a los alumnos el reto de saber vivir más humanamente (Gil y Manley-Casimir, 2004) esto es, de empeñarse en dar una envergadura universal a los horizontes de existencia más local: "Que allí donde estés logres para todos más libertad, más justicia, más igualdad, más pluralismo, más tolerancia, más solidaridad...”. Los educadores no pueden conformarse así con los derechos escritos, con los realmente "positivizados", porque sus aspiraciones no se reducen a cumplir sólo con lo ya establecido, conseguido o reconocido, sino que deben ayudar a alcanzar realidades mejores, sociedades más justas, familias más acogedoras y formativas, escuelas más educativas, relaciones humanas más solidarias...

12. Por eso, no es casualidad que destacados juristas, sobre todo, cercanos a las consideraciones antropológicas de la filosofía del derecho se terminen interesando por la educación.

13. No hay que extrañarse, por tanto, cuando algunos relatores de la ONU para el derecho a la educación empiezan a considerar muy seriamente, como le pasa a Katarina Tomasevski, que puede haber peores sistemas educativos que la ausencia de escolarización (2003). 
Una teoría educativa de los derechos humanos nos puede ayudar a reconocer que su enseñanza no es sólo una cuestión técnico jurídica de derechos positivizados, ni sólo una aspiración ética de concepción humanizadora de trato. Poner a nuestros alumnos y educadores frente a estos derechos es situarnos en una concepción antropológica determinada. Tal vez la enseñanza de derechos humanos deba ser contemplada en primaria y secundaria como la primera clase de antropología, una clase llena de espejos donde se informe quiénes somos como personas, a qué pretendemos aspirar y por qué. Una clase con eco biográfico, que permita una lectura antropológica y ética de la búsqueda de identidad personal, donde se resalte frente a las legítimas y convenientes múltiples formas de ser, los ideales básicos de realización personal.

Esa visión apasionada es la misma que tiene que acompañar al educador para poder trasmitir a sus alumnos que, tras las múltiples formas de llegar a ser, compartimos unos ideales básicos de realización personal y social. Un buen educador tiene que cultivar la necesaria sensibilidad para mirar con respeto y simpatía la búsqueda de identidad de sus alumnos. Pienso que esa mirada puede tener mayor alcance pedagógico y, por tanto, puede ayudar a madurar más y mejor si los educadores reflexionan sobre las necesidades del desarrollo humanizador. Los derechos humanos contribuyen así, en una parte muy importante, a comprender esas necesidades y sus plurales expresiones, precisamente, en lo que consiste la tarea educativa.

Creo que la lectura y estudio de las diversas declaraciones internacionales de derechos humanos por parte de los educadores puede contribuir decisivamente a definir las intenciones educativas situando a la persona en el centro radical de las tareas educativas. Los educadores mantienen una mirada antropológica sobre las bases comprensivas de la condición humana cuando atienden a los valores o fines de las grandes declaraciones de derechos humanos. Por eso, es imprescindible que quien aspire a ser un buen educador lea y analice estas declaraciones pues le van a propiciar unos sólidos pilares de intenciones educativas al reparar en fines consensuados sobre la condición humana y en una visión apasionada de las posibilidades del progreso moral del ser humano. La mirada sobre los fines de la persona, o es antropológica y filosófica en un primer análisis, o es ciega para entender la dinámica interna de la formación humana.

Pero, probablemente, la contribución más interesante del marco interpretativo y crítico de los derechos humanos a las bases éticas de la educación sea el hecho mismo de agitarlas, de provocar que no nos conformemos con nuestras prácticas educativas actuales, con lo que nos dicen que son los fines de la persona, con la idea de hombre o mujer y su desarrollo humanizador, y que, por el contrario, estemos alertas ante las expectativas hacia formas más acertadas y consideradas sobre lo que vamos sabiendo de la condición humana, "lo que se entiende por conocer, emocionarnos o desarrollarnos como seres éticos" (García del Dujo, García Carrasco y Asensio, 2006, 216). 


\section{IGUALDAD Y DIGNIDAD HUMANA}

Como es sabido la dificultad de la educación, entre otras, estriba en equilibrar adecuadamente la conservación y el cambio, el consenso y el disenso, los acuerdos y desacuerdos, la aceptación y el rechazo, los síes y los noes... Un aspecto básico para la educación es reconocer que formamos para el cambio, para el dinamismo. No somos policías, ni guardianes de lo logrado sino cultivadores de semillas de sueños no cumplidos y, sí, en efecto, esto puede ser, y la historia lo demuestra, muy peligroso. Los educadores enseñamos un estado de cosas con la esperanza de engendrar el descontento suficiente, la expectativa incumplida, la aspiración a mejorar. Probablemente, el disenso sea el horizonte del perfil ideal del hombre educado: son algunos sujetos los que divisan intuitivamente, con perspectiva moral muy aguda, nuevas formas de ser humanos y de tratarnos humanamente, hasta de tratar con señorial humanidad al entorno en todas sus variantes animadas e inanimadas. Y esto, como es lógico, tiene su propia dinámica interna: excesos, tibiezas, prisas, tardanzas, desmesuras, prudencias, etc. (Jover, 2004, 90 y ss.).

Sobre esta dinámica interna del disenso querría apuntar, en este último apartado, unas cuestiones. Cuestiones que afectan a las finalidades de la enseñanza de los derechos humanos, al sentido pedagógicamente distintivo de su presencia en el currículo escolar. Políticamente, se ha aceptado y generalizado la idea de que el límite de la dinámica interna del disenso pasa por cualquier propuesta que impida disensos futuros. Tiene mucha lógica que no aceptemos como postura crítica o contraria a los consensos establecidos cualquiera que prohíba e impida, en sus diversas formas, más disensos, esto es, propuestas que se vean a sí mismas como el fin final de la historia.

Pues bien, pedagógicamente tiene también mucha lógica que las finalidades educativas en torno al disenso hagan referencia a la idea de progreso moral y de retroceso moral. La formación sobre los derechos humanos sólo puede ser contemplada como expectativa de disenso político y moral de la realidad si estamos convencidos, realmente convencidos, de que hay avances y retrocesos, que hay errores y aciertos, que hay sendas más humanizadoras y otras deshumanizadoras. La fuerza de estos derechos, su capacidad de protección a los más débiles, su ayuda para divisar disensos deseables sólo es posible si asumimos que, en rigor, lo que estamos intentando alcanzar son verdades prácticas sobre la condición humana, sobre modos de ser y de crecer, de ser y tratarnos más humanamente. Detrás de los nuevos consensos de valores y detrás de los disensos no hay sólo malabarismos técnicos, jurídicos, sobre situaciones o estados de cosas, de poderes particulares, sino sobre todo una idea intuitiva de lo que vamos pensando que es el hombre, nuevos modos de ver (Escámez, 2007, 223).

Pues bien, el campo de significado de estas verdades prácticas, de la idea de progreso y retroceso moral frente a las diferentes propuestas de disensos y consensos, pasa necesariamente en la formación de las nuevas generaciones por trasmitir una idea de la dignidad humana. La educación en derechos humanos debe 
alcanzar, más allá de sus declaraciones o convenciones, instancias jurídicas, estructuras de poder o generaciones de derechos, etc., a su fundamentación en la idea de la igual dignidad de los seres humanos. Ésta es, a nuestro juicio, la gran contribución formativa de estos derechos. Veámoslo con más detalle.

El reconocimiento de esta igualdad, como punto de partida, debe alcanzar la perspectiva moral que abre la idea de la dignidad humana porque no nos basta que los alumnos aprendan un dato antropológico sino que reconozcan un criterio de valor ético, el criterio, moralmente exigente, de ser persona y de estar entre personas. La experiencia muestra que para enseñar las diferencias no hace falta una intencionalidad sistemática: los contextos culturales no formales e informales de convivencia ya facilitan este acercamiento, es un aprendizaje empírico, visual y hasta adquirido sentimentalmente. Mientras que el objetivo educativo de la común dignidad es una adquisición que requiere procesos más sistemáticos pues se opone o, por lo menos, carece de apoyo empírico, visual ${ }^{14}$. Sin embargo, cabe justificar que el logro del respeto a las diferencias requiere del aprendizaje de esa igualdad básica entre los seres humanos.

Todavía está muy extendida la tendencia a fundamentar la dignidad humana en la sobresaliente actuación de ciertos sujetos, lo cual es acertado para resaltar lo que en la filosofía tradicional se conoce como "segunda dignidad": la especial capacidad y el peculiar empeño de algunos hombres en particular por lograr una singular soberanía y excelencia en el recto ejercicio de sus libertades. Sin embargo, la idea de la dignidad humana en su sentido más radical no puede interpretarse sólo desde esta perspectiva pues estaríamos negando o, cuando menos, cuestionando la titularidad de ese valor esencial y primigenio a quienes por defecto, inmadurez o deterioro no son, por cierto, sobresalientes ni incluso capaces de ejercitar las superiores capacidades humanas, lo que en el fondo sería tanto como negarles su peculiar condición personal, su derecho a ser hombres, a aspirar y a ser ayudados a alcanzar los mejores modos de vida que les quepa desarrollar.

La fundamentación liberal-individualista tiende a considerar la dignidad humana desde la posesión de ciertas capacidades que generan autonomía. Esta perspectiva es excluyente de raíz y si bien hay que reconocer el peso que tuvo, en su momento, para vislumbrar intuitivamente la idea de la dignidad humana, su generalización deja fuera del reconocimiento de dicha dignidad a colectivos enteros. No cabe duda de que el progresivo reconocimiento de la dignidad humana tiene que apoyarse necesariamente en la búsqueda de una autonomía emancipatoria, pero su fundamentación tiene que ser más amplia y radical para que no queden

14. En sucesivas investigaciones de campo, con metodologías narrativas, hemos comprobado cómo los niños y las niñas tienden a mantener un concepto de la igualdad sujeto exclusivamente a las capacidades poseídas y, sobre todo, a los actos realizados. De tal modo, que para ellos, las personas ganan y pierden en "dignidad", en la medida que se comportan de un modo o de otro. 
fuera, como se ha dicho, aquellos que no pueden por sí mismos participar, por las razones que sean, de esa autonomía (García Carrasco, 2007).

De este modo, la dignidad humana sólo puede constituirse en el verdadero fundamento de una ética universal y en la aspiración dinamizadora y alentadora de la evolución y extensión de la misma cuando se conciba en términos referidos al recíproco reconocimiento y aprecio entre los hombres de que la condición humana y su pleno desarrollo tiene un valor intrínseco.

Y ello porque la dignidad es indivisible, no reside en ciertas características del ser humano aisladamente consideradas, sino en el ser humano como tal en su unidad indivisible. No habría por tanto seres humanos más dignos que otros, ni vidas más dignas que otras. En definitiva, se trata de mantener la prioridad de los individuos y de sus derechos, pero no de un individuo en abstracto, sino de los individuos concretos, reales, existentes en su diversidad y complejidad (Fernández Ruiz-Gálvez, 2003, 49).

Para lograr el efecto educativo adecuado en la enseñanza del reconocimiento de la dignidad humana, es necesario que el aprendizaje de esta igualdad básica entre todos los seres humanos se complemente con la idea de los derechos humanos como medio de protección universal de esa dignidad. En efecto, la manifestación jurídica del reconocimiento de la dignidad humana se expresará en la protección necesaria para que cada hombre pueda participar de un conjunto fundamental de derechos iguales para todos, así como en respetar mediante un trato cada vez más humano los particulares proyectos personales de vida que cada sujeto decida desarrollar desde esa participación común a toda la humanidad.

La idea de la dignidad humana tiene que considerarse, entonces, desde una perspectiva pedagógica que sepa armonizar, por un lado, lo universal y lo particular, esto es, el valor de todo ser humano y el valor de cada ser humano, de cada proyecto particular de vida.

La dignidad humana y su protección jurídica a través de los derechos humanos nos aportan un criterio o expectativa de moralidad que es a un mismo tiempo universal y particular: el derecho a ser hombre y a ser tratado humanamente (Bárcena, Gil y Jover, 1999). El derecho a ser hombre es un criterio moral universal porque abarca a todos los hombres en lo que tienen más de común: su inacabamiento como tarea irrenunciable. Por otra parte, es un criterio moral particular porque el derecho a ser hombre (la tarea de hacernos) es una empresa en la que somos insustituibles: se concreta en voluntades individuales que expresan con mayor o menor empeño y acierto su capacidad de valorar, de reinterpretar la herencia recibida según los intereses y necesidades personales. El sentido universalista y particular del derecho a ser hombre permite descubrir así un ideal común de humanidad en tensión dialéctica con un ideal del yo particular. Quien es consciente de esta tensión también lo será de la responsabilidad individual de mantener su ideal del yo sin esperar a la intervención del Estado, de las instituciones o de los grupos sociales. Quien es consciente de esa tensión también lo será de la responsabilidad 
común con otros individuos de saber valorar el empeño de otros ideales del yo distintos y hasta opuestos al propio, por su colaboración en elaborar nuevos ideales de humanidad. Necesito a los otros con sus particulares formas de querer ser hombres para que mi tensión individual -mi historia particular- entre el ideal del yo que quiero darme y el ideal común de humanidad que diviso no lleguen nunca a identificarse, esto es, ni llegar a absolutizar mi proyecto personal de vida que es el riesgo trágico en cualquier búsqueda de la excelencia personal, ni llegar a absolutizar tampoco las formas de vida actuales que es la enfermedad del miope existencial.

La idea de la dignidad humana puede, así, suscitar efectos educativos muy deseables cuando la integramos en el currículo escolar. Parece muy conveniente que, en todas las asignaturas pero especialmente en la enseñanza de los derechos humanos, los alumnos aprendan a destacar el valor preeminente del ser humano en los productos, procesos y aplicaciones del progreso científico, tecnológico y humanístico. Situar a la persona en el centro de todo significa reconocer su valor moral, su dignidad humana, aprender a adquirir una razón comprometida. Estos aprendizajes cognitivos y actitudinales pueden tener una especial resonancia formativa en la adolescencia. La adquisición en este periodo de una identidad personal más consistente justifica psicológica y pedagógicamente esta propuesta. En efecto, durante estos años hay una mayor preocupación por la vida personal a fin de consolidar una identidad bien estructurada. Ésta se desarrolla, principalmente, a través de tres procesos: una conciencia moral autónoma de reciprocidad, una adopción de valores significativos y un concepto positivo de sí mismo. No cabe duda de que es un momento propicio para plantearse la enseñanza de la dignidad humana y de su concreción jurídica en los derechos humanos. Mientras que el adolescente tiende a asumir aquellas ideas y valores que le comportan una autoestima positiva y una identidad concreta, la enseñanza de derechos humanos le permite descubrir, como hemos visto, tanto el valor general de la humanidad como de cada persona. Por otro lado, al tiempo que el adolescente se afana por establecer criterios de actuación autónomos, los derechos humanos son una propuesta para adoptar comportamientos sociales y personales de carácter humanizador ${ }^{15}$.

De este modo, la singularidad de la enseñanza de los derechos humanos radica en que el docente sepa relacionar el conocimiento y la valoración positiva de esos derechos con los procesos de autonomía moral en los que se encuentra el sujeto. En definitiva, se trata de conseguir que los derechos humanos constituyan una parte relevante de los valores que el adolescente va a ir adquiriendo y que le ayuden a conquistar una mayor autonomía personal. Para que la idea de la dignidad

15. Hay ciertos errores pedagógicos graves cuando se considera, como hace Rivera (2007, 36 y ss.), no sin cierta gracia, eso hay que reconocerlo, que sólo, radicalmente, sólo educan en general y, en particular, con respecto a la ciudadanía, los grupos de iguales. Otra perspectiva, de la misma cuestión, esta vez sí más seria, es la que plantea ReYero con respecto a la libertad individual y las relaciones con los otros como otras libertades (2006a, 186,190 y ss.; vid. 2006b, sus interesantes comentarios virtuales sobre estas cuestiones). 
humana y de los derechos humanos pueda constituirse en una de las aportaciones lógica y psicológicamente más relevante para los procesos cognitivos y psicológicos de la adolescencia, hay que ayudar al alumno a reparar en que el derecho a ser hombre consiste, por un lado, en el derecho a desarrollar libremente nuestro proyecto personal de vida sin que nadie pueda realizarlo por nosotros $y$, por otro, el deber de caracterizar bumanamente ese proyecto sin que nadie pueda bumanizarlo por nosotros.

Por eso, el modo de conseguir que la dignidad humana se constituya en criterio de valoración para el alumno consiste en enfrentarle a situaciones sociales ${ }^{16}$ en las que tenga que emprender acciones de ayuda humanitaria, donde podrá percibir "en su propia piel" el derecho a ser hombre, a ser tratado humanamente, a entender el trato amistoso y, en su caso, compasivo (Bárcena, 2007; Ortega y Mínguez, 2007). El docente puede conseguir este objetivo fomentando tres tipos de actividades: la prestación de algún servicio social; la realización de ayudas desinteresadas; la participación en cuestiones cívicas.

Conviene reparar, pues, en que la enseñanza de la igualdad humana, del criterio y expectativa sociomoral de la dignidad humana debe, por un lado, precisamente, por el lado jurídico, vincularse con el conocimiento de diversas Declaraciones y Convenios. Pero, al mismo tiempo, la enseñanza de esa dignidad debe vincularse por su vertiente antropológica y ética, mostrando al alumnado la insuficiencia radical de todo conjunto de derechos para lograr extender un trato humano. Puedo así mantenerme dentro de la legalidad vigente, sin que nada ni nadie pueda denunciar jurídicamente mi comportamiento y, sin embargo, ser humanamente injusto. Intuir lo que humanamente no se ajusta a una idea de ser humano, por muy regulado y aceptado que esté en la legislación vigente, es el inicio del disenso, de la probabilidad del progreso moral.

\section{BiBLIOGRAFÍA}

Ayuste, A. (2006) Las contribuciones de Habermas y Freire a una teoría de la educación democrática centrada en la deliberación racional y el diálogo, en AYUSTE, A. Educación, Ciudadania y Democracia. Barcelona, Octaedro-OEI, 65-102.

BÁrCENA, F. (2007) Las tareas de una nueva filosofía política. Una reflexión acerca de la amistad política, Cuadernos de Alzate, 36, 59-80.

BÁrcena, F.; Gil, F. y Jover, G. (1999) La socialización como forma de educación moral, en BÁrCena, F.; Gil, F. y Jover, G. La escuela de la ciudadanía. Educación, ética y política. Bilbao, Desclée de Brouwer, 43-70.

CAmps, V. (2007) Educar para la ciudadania. Sevilla, Ecoem.

16. “Una comunidad democrática debe instituir prácticas de valor que faciliten la cooperación entre sus miembros y la experiencia de valores encarnados en formas de comportamiento" (PUIG ROviRA, 2000, 187). Vid. Puig, Batlle, Bosch y Palos, 2007. 
Escámez, J. (2007) Las aportaciones de la teoría de la educación, Revista española de pedagogia, 65 (237), 217-236.

Fernández Liria, C.; Fernández Liria, P. y Alegre Zahonero, L. (2007) Educación para la ciudadanía. Democracia, Capitalismo y Estado de Derecho (2. ${ }^{a}$ edición). Madrid, Akal.

FERnández Ruiz-Gálvez, E. (2003) Igualdad y derechos humanos. Madrid, Tecnos.

GadAmer, H.-G. (1977) Verdad y método. Salamanca, Sígueme.

García Carrasco, J. (2007) Leer en la cara y en el mundo. Barcelona, Herder.

García del Dujo, A.; García Carrasco, J. y Asensio, J. M. (2006) Hechos y pensamientos sobre educación en busca de una teoría: la trama entre biología, tecnología y cultura, Revista Portuguesa de Pedagogía, 40 (1), 197-221.

GiL, F. (2003) Elaboración de una teoría pedagógica de los derechos humanos, en RuIz CoRBELLA, M. (coord.). Educación moral: aprender a ser, aprender a convivir. Barcelona, Ariel, 71-89.

GiL, F. y Jover, G. (2003) La contribución de la educación ética y política en la formación del ciudadano, Revista de Educación, número extraordinario del 2003: "Ciudadanía y Educación", 109-130.

Gil, F. y Manley-Casimir, M. E. (2004) Perspectives on Human Rights and Education, Encounters on Education, número monográfico sobre "Education and human rights", 5, Fall, 1-8.

Hierro, L. L. (2002) El concepto de justicia y la teoría de los derechos, en DíAz, E. y ColoMER, J. L. (eds.). Estado, justicia, derechos. Madrid, Alianza.

Ibáñez-Martín, J. A. (2000) Los profesores como constructores de la paz, Revista española de pedagogia, 58 (216), 235-252.

Jover, G. (2004) Civilización, desarrollo y derechos humanos: propuestas de cooperación, en Sociedad Española de Pedagogía. La educación en contextos multiculturales: diversidad e identidad. XIII Congreso Nacional y II Iberoamericano de Pedagogía. Ponencias. Valencia, SEP, 83-100.

Jover, G.; Casares, P.; Gil, F. y PayÁ, M. (2001) La crisis de la sociedad actual, en Ortega, P. (coord.). Conflicto, violencia y educación. Seminario Interuniversitario de Teoría de la Educación. Murcia, Caja Murcia, 9-76.

KIWAN, D. (2005) Human rights and citizenship: an unjustifiable conflation, Journal of Philosophy of Education, 39 (1), 37-50.

MarTínez, M. y Hoyos, G. (2006) Educación para la ciudadanía en tiempos de globalización, en Martínez, M. y Hoyos, G. (eds.). La Formación en valores en sociedades democráticas. Madrid, Octaedro-OEI, 15-48.

Mestre, J. V. (2007) La necesidad de la educación en derechos humanos. Barcelona, UOC.

Muguerza, J. (2007) Ética pública, derechos humamos y cosmopolitismo, en Gómez, C. y Muguerza, J. (eds.). La aventura de la moralidad (paradigmas, fronteras y problemas de la ética). Madrid, Alianza, 510-549.

Naval, C. y Jover, G. (2006) The Research on Moral and Civic Education in the Spanish Educational Theory: evolution and current trends, Journal of Social Science Education, 5 (2), 93-104.

Nussbaum, M. (2002) Education for citizenship in an era of global connection, Studies in Philosophy and Education, 21, 289-303.

Ortega, P. y Mínguez, R. (2007) La compasión en la moral de A. Schopenhauer. Sus implicaciones pedagógicas, Teoría de la Educación. Revista Interuniversitaria, 19, 117-137. 
Peces-Barba, G. (2006) La incorporación del derecho y de los derechos humanos en la educación, en RibotTA, S. (ed.). Educación en derechos humanos. La asignatura pendiente. Madrid, Dykinson, 25-44.

- (2007) Educación para la ciudadanía y derechos bumanos. Madrid, Espasa Calpe.

PÉreZ-Luño, A.-E. (1986) Los derechos fundamentales. Madrid, Tecnos.

Puig Rovira, J. M. ${ }^{a}$ (2000) La escuela como comunidad democrática, Encounters on Education, 1, Fall, 167-188.

Puig Rovira, J. M. ${ }^{a}$; Batlle, R.; Bosch, C. y Palos, J. (2007) Aprendizaje servicio. Educarpara la ciudadanía. Barcelona, Octaedro-MEC.

Reyero, D. (2006a) ¿Pero todavía alguien cree que es posible la educación cívica?, en NAval, C. y Herrero, M. (eds.). Educación y ciudadanía en una sociedad democrática. Madrid, Encuentro, 181-196.

- (2006b) El Estado debe formar ciudadanos... (y los lobos deben cuidar gallineros) (julio, 18); Más sobre ciudadanía (agosto, 31); Cuando la realidad supera a la ficción. Lección 1 de educación para la ciudadanía (octubre, 1). http://www.junkeducation. com/index.html (última consulta: 9 de enero de 2007).

Rivera, J. A. (2007) ¿Cómo educar en valores? Sobre Educación para la Ciudadanía, Claves de Razón Práctica, 176, octubre, 34-41.

Soriano, A. (2007) Los caminos de la educación cívico-moral. Un debate permanente, Teoría de la Educación. Revista Interuniversitaria, 19, 73-97.

Tomasevski, K. (2003) El asalto a la educación. Madrid, Inrtermon Oxfam.

Touriñán, J. M. (2003) Sociedad civil y educación de la conciencia moral, Teoría de la Educación. Revista Interuniversitaria, 15, 213-234. 